\title{
A new species of Hemigrammus Gill, 1858 (Characiformes: Characidae) from Río Caura, Venezuela
}

\author{
RICARDO C. BENINE ${ }^{1} \&$ GUILHERME A. M. LOPES ${ }^{1,2}$ \\ ${ }^{1}$ Laboratório de Biologia e Genética de Peixes, Departamento de Morfologia, IBB-UNESP Campus de Botucatu, Botucatu, SP, 18618 - \\ 000,Brazil.E-mail: rbenine@ibb.unesp.br \\ ${ }^{1,2}$ Programa de Pós-Graduação em Ciências Biológicas, área de Zoologia, IBB-UNESP, Campus de Botucatu, Botucatu, SP, 18618- \\ 000, Brazil
}

\begin{abstract}
A new characid species, Hemigrammus taphorni, is described from the Río Caura drainage, Venezuela. The new species is distinguished from its congeners by characters related to its color pattern, number of scale rows below the lateral line, teeth morphology, and dorsal-fin length. A brief discussion about the putative relationships of $H$. taphorni is provided.
\end{abstract}

Key words: Systematics, Neotropical tetras, Hemigrammus elegans

\section{Introduction}

The genus Hemigrammus Gill, 1858 is one of the most diverse in the Characidae, presently with 45 species recognized as valid and widely distributed in Neotropical cis-andean river basins (Lima et al., 2003; Bertaco \& Carvalho, 2005, Zarske et al. 2006). Currently allocated as incertae sedis in Characidae (see Lima et al., 2003), Hemigrammus has not been investigated since the monograph of Géry (1977). Géry, based on the extensive revision of the genus presented by Marion Durbin Ellis in Eigenmann (1918), defined Hemigrammus by the presence of premaxillary teeth in two rows, inner row with five or more teeth, scale sheath covering the caudal-fin lobes, and an incomplete lateral line. According to Bertaco \& Carvalho (2005), the notable anatomical diversity within Hemigrammus and the high number of species recognized are likely to be the major reasons behind the lack of phylogenetic analyses of its species, as well as of the genus among characids. Examination of several lots from Museo de Ciencias Naturales de Guanare, Venezuela, revealed a new and sexually dimorphic species of Hemigrammus, which is described herein.

\section{Material and methods}

The material examined in this study is deposited in the Laboratório de Biologia e Genética de Peixes (LBP), UNESP, Botucatu (São Paulo state, Brazil), Museo de Ciências Naturales de Guanare (MCNG), Guanare (Venezuela), and Museu de Zoologia da Universidade de São Paulo (MZUSP), São Paulo (Brazil). Morphometric and meristic data for 39 specimens were taken following Fink \& Weitzman (1974). Linear regression analyses were performed using Excel (vers. 2003, Microsoft Corp.) to describe the quantitative relationships between standard length and dorsal fin length in males and females/imatures. In the description, counts are followed by their frequency in parentheses. Asterisks indicate values for the holotype. Vertebrae of the Weberian apparatus were counted as four elements and the fused PU1+U1 of the caudal region as a single element. 